Macpherson, F. (2014) Is the sense-data theory a representationalist theory? Ratio, 27 (4). pp. 369-392. ISSN 0034-0006

Copyright (C) 2014 The Author

http://eprints.gla.ac.uk/98140

Deposited on: 17 November 2014

Enlighten - Research publications by members of the University of Glasgow http://eprints.gla.ac.uk 
(C) 2014 The Author. Ratio Published by John Wiley \& Sons Ltd.

This is an open access article under the terms of the Creative Commons Attribution License, which permits use, distribution and reproduction in any medium, provided the original work is properly cited.

Ratio (new series) XXVII 4 December 2014 0034-0006

\title{
IS THE SENSE-DATA THEORY A REPRESENTATIONALIST THEORY?
}

\author{
Fiona Macpherson
}

\begin{abstract}
Is the sense-data theory, otherwise known as indirect realism, a form of representationalism? This question has been underexplored in the extant literature, and to the extent that there is discussion, contemporary authors disagree. There are many different variants of representationalism, and differences between these variants that some people have taken to be inconsequential turn out to be key factors in whether the sense-data theory is a form of representationalism. Chief among these are whether a representationalist takes the phenomenal character of an experience to be explicable in virtue of the properties of an experience that represent something or explicable in virtue of that which gets represented. Another is whether representationalists hold a nonreductionist, or naturalistically or non-naturalistically reductionist variant of representationalism. In addition, subtle differences in what one takes phenomenal character to be on the sense-data theory - either awareness of sense-data or the sense-data themselves - together with one's account of representation, are crucial factors in determining whether sense-data theory is compatible with representationalism. This paper explores these relationships and makes manifest the complexities of the metaphysics of two central theories of perception. ${ }^{1}$
\end{abstract}

\section{Introduction}

Is the sense-data theory of perception - otherwise known as indirect realism - a representationalist theory of perception? This question has not received much attention in the literature, despite two facts. First, representationalism and sense-data theory are two major theories in the philosophy of perception and discussions of

1 Many thanks are due to Clare Batty, Derek Brown, and James Stazicker for discussion and feedback on earlier drafts, which made this essay better than it would otherwise have been. This work was supported by two grants from the Arts and Humanities Research Council (grant numbers AH/I027509/1 and AH/L007053/1). 
them are extensive. Second, those philosophers that have discussed this question have provided different answers to it.

In this paper I seek to answer the question and, in doing so, explain why people have given different answers. Unsurprisingly, the answer turns out to depend on which version of representationalism and which version of indirect realism one considers. However, there are more versions of each than one might have expected, and whether indirect realism is a representationalist theory turns on different factors in different cases.

I will proceed, in section two, by explaining the theory of perception and its account of perceptual experience known as 'representationalism'. There are many different varieties of representationalism, and consensus does not exist on which theories the term should cover. In section three, I will explicate the indirect theory of perception and its account of perceptual experience, and outline the varieties of this theory. In section four, I will consider which varieties of indirect realism are compatible with minimal representationalism. In section five, I consider which varieties of indirect realism are compatible with weak, strong, and reductive forms of representationalism. In so doing, I shed light on the significance of the different varieties of each of these views, and bring to light some important considerations about the nature of representation.

\section{Representationalism}

Representationalism is a theory that says something about representation and something about phenomenal character. I begin this section with short standard elucidations of these terms. Further elaboration of them then occurs throughout this essay. I then consider the different forms of representationalism.

The term 'phenomenal character' refers to 'what it is like' for subjects to have certain mental states. ${ }^{2}$ Think of your favourite perceptual experience - a visual experience of the sky at twilight when the sky is midnight blue, perhaps. There is something that it is like to see that shade of blue, and what it is like is crucial to your having that experience. Of course when you see an expanse of blue there are typically all sorts of other conscious states that

\footnotetext{
2 Nagel (1974) introduced the famous 'what it is like' locution into philosophical literature.
} 
you are in at the same time. You might auditorily experience the sound of voices and clinking glasses, you might be aware of the position of your body lying back on the grass, you might think about what you are going to eat for dinner, and feel tired, and so on. In thinking about what it is like to see something blue you are supposed to abstract away from all the other experiences and conscious states that you are having and consider only that part of your conscious mental life that corresponds to visually experiencing the colour of the sky. ${ }^{3}$ If there was nothing that it was like to experience the colour of the sky, then you wouldn't be having that experience at all. If there was something different that it was like, then you would be having a different kind of experience perhaps you would be having a visual experience of a light blue sky, or the visual experience that you are having right now as you read this page. Or, indeed, you might not be having a perceptual experience at all but some other state with phenomenal character, for example, a sensation such as a pain state. Mental states with phenomenal character include perceptual experiences, such as those involved in seeing red squares, hearing music, or tasting whisky; bodily sensations such as itches, tickles, and pains; and emotions or moods, such as feelings of fear, jealousy, and depression. Memories and imaginings of such states often have phenomenal character too. It is a contested issue whether judgments, thoughts, or occurrent beliefs ever have phenomenal character or whether such states are simply accompanied by other states that do - typically imagery states.

Note that 'phenomenal character' is taken to be a philosophically neutral term that leaves open the ontological and epistemological nature of states with phenomenal character. Thus, for example, holding that there is phenomenal character does not commit one to a dualist, physicalist or functionalist account of the mind, nor does it commit one to thinking that we have or lack infallible or indubitable knowledge of elements our own mind. In this respect, it is unlike the term 'qualia', which is often taken to indicate commitments to a dualist perspective and special knowledge of phenomenal states.

3 Whether or not it is possible to do such abstraction turns on the extent to which experience is essentially multimodal. While I think that some experiences are essentially multi modal - see Macpherson (2011) - I don't believe that all are. I believe that the sort of abstraction called for is frequently possible.

4 This debate - the cognitive phenomenology debate - is examined in Bayne and Montague (2011). 
Representational states are states that are about, or are directed towards, something. The paradigm representational states are beliefs and judgments. Your judgment that Scotland is the best country in the world is about Scotland and how good it is. Think of your visual experience of the black letters on this white background (the paper or the screen). The experience, one might think, seems to be about the letters, the background, and their respective colours. In having the experience, your mind is directed towards these things. Elucidated thus, representation might seem a rather straightforward concept. In fact, there are a host of complexities lurking behind the simple description that I have just given. Spelling out what it is for a state to be representational is a subject of much debate, as will become clear later in this essay.

Representationalism is perhaps the most popular theory of the nature of experience in contemporary analytic philosophy. It comes in three different strengths: minimal, weak and strong. Cross-cutting those distinctions, representationalism can also come in what I will call a 'feature of experience' and a 'representational content' variety. It can also come in a reductive and a non-reductive variety. I will begin by explicating the distinction between minimal, weak and strong varieties.

According to the most minimal form of representationalism, experiences are, at least sometimes, representational states. More particularly, the claim is that the phenomenal character of experience is, at least sometimes, representational. A stronger claim is that that all phenomenal character is representational. I will call a position that affirms either of these two claims, but which does not go on to make the further claims of weak and strong representationalism that I outline below, 'minimal representationalism'.

Representationalists often make stronger claims than that demanded by minimal representationalism. One such claim is that phenomenal character is always representational and that there can be no difference in the phenomenal character of experience without a difference in the representational content of experience. The second part of this claim is the claim that the phenomenal supervenes on the representational. ${ }^{5}$ Consider your experience of

When using the term 'supervenience' I mean only to indicate the claim that there can be no difference in one set of properties without a difference in another set of properties. I do not mean to further imply or deny that there is a determination relation between the subvenient and supervenient properties. Sometimes, but not always, 'supervenience' is used to indicate that there is a determination relation present, sometimes a determination relation specifically less strong than that of identity or reduction. 
the midnight blue sky. It has a particular phenomenal character and, as I said previously, this experience plausibly represents midnight blue. Suppose that it does. The supervenience claim guarantees that any experience that has a different phenomenal character will not represent midnight blue but something else instead. Following Tye (2009) I will call a representationalist theory that endorses these claims, but not the still stronger claims that I am about to outline, 'weak representationalism'.

'Strong representationalism' is the view that not only does phenomenal character supervene on representational content, but representational content supervenes on phenomenal character. Again, consider your experience of the midnight blue sky and suppose that it represents midnight blue. What is being claimed is that all experiences that represent midnight blue will have that phenomenal character and all experiences with that phenomenal character will represent midnight blue. I will call this claim the 'mutual supervenience of the phenomenal and the representational'. The mutual supervenience of the phenomenal and the representational has great prima facie plausibility. Experiences with the typical phenomenal character had while looking at midnight blue and experiences with the typical phenomenal character had while looking at yellow ochre always seem to represent different colours - midnight blue and yellow ochre respectively. Likewise, experiences that represent midnight blue and experiences that represent yellow ochre always seem to have different phenomenal characters. Indeed, it is hard to imagine how two experiences that were the same in what it was like to have them could represent different things. What would indicate to one that there was this difference between them? Some strong representational theorists hold that the simplest explanation of the mutual supervenience of the phenomenal and the representational is that phenomenal character is identical to the representational nature of experience. Again, following Tye (2009), I will call views that endorse either the mutual supervenience of the phenomenal and the representational, or the type-identity of the two, 'strong representationalist' views. ${ }^{6}$

Orthogonal to these distinctions between minimal, weak, and strong representationalism is the distinction between 'feature of experience' types of representationalism and 'representational

6 The terms 'weak representationalism' and 'strong representationalism' are, unfortunately, not used consistently in the extant literature. Compare, for example, Chalmers (2004), Lycan (2006) and Tye (2009). Tye's usage is most convenient for my purposes. 
content' types of representationalism. To understand the difference, consider again minimal representationalism. This was the view that phenomenal character is either at least sometimes, or always, representational, but that there are no supervenience relations between phenomenal character and representation. The feature of experience version of this view is that the phenomenal character of an experience is a feature (in other words a property) of an experience and this feature sometimes or always represents. To take an example, the phenomenal character of an experience of seeing midnight blue would be a feature of the experience (one might call it 'phenomenal blue') and it might represent something on a particular occasion - most plausibly, it might represent midnight blue.

One can be a weak representationalist or a strong representationalist and hold the feature of experience view by, in the former case, adding the claim that phenomenal character supervenes on representational content to the view just spelled out and, in the latter case, by in addition adding the claim that representational content also supervenes on phenomenal character. If one makes the stronger claim still that phenomenal character and representation are identical then one will not hold that phenomenal character has the property of representing certain things but that the property of having a certain phenomenal character just is the property of representing certain things. The feature of experience account of representationalism is the way that Chalmers (2004) understands representationalism. ${ }^{7}$

The alternative to the feature of experience view is the "representational content' view. On this view, phenomenal character is sometimes or always to be identified with the representational contents of a mental state. There are two main views of what the contents of a mental state are. On one, the contents are a proposition, namely, that which is introduced by a 'that' clause. On another, the contents are to be identified with the objects, properties and relations that are represented - a Russellian view of content. I will write only about the Russellian version of the representational content view in the rest of this paper, and call it the 'representational content view' because so many prominent representationalists advocate this view, and for sake of parsimony.

\footnotetext{
Rather than talk of phenomenal character, Chalmers (2004: 341) talks about phenomenal properties, which he takes to be properties of experiences (and properties of subjects of experience).
} 
Therefore, for the rest of the paper, I will ignore the former version of the view. The reader should duly note this fact.

On the Russellian version of this view then, the phenomenal character of an experience of seeing midnight blue, for example, would be identical with the content of that experience, namely, identical with the property midnight blue (as opposed to the property of representing midnight blue). The representational content form of representationalism therefore denies that phenomenal character is a property of an experience, strictly speaking, although it may wish to maintain that we can say, very loosely and informally, that phenomenal character is something that experience has. Rather, it says that phenomenal character is, sometimes or always, the representational content of an experience, namely, that which gets represented by an experience. This is the way that Tye $(1995,2000$, and 2009) and Dretske (1995) spell out representationalism.

One can be a minimal representationalist, a weak representationalist, or a strong representationalist and hold the representational content view. On the minimal view one would have to hold that sometimes or always particular token instances of phenomenal character are identical with particular token instances of properties or of objects, or at least the temporal part of the token instances of properties or of objects that corresponded to the temporal existence of the phenomenal character. One would be a weak representationalist by adding the claim that types of phenomenal character, such as the type of phenomenal character had by your experience of the midnight blue sky, supervene on types of representational content, such as the property blue. And one could be a strong representationalist by, in addition, holding the claim that types of representational content supervene on types of phenomenal character or the stronger claim that types of representational content are identical with types of representational content.

The astute reader will have noticed that, when first outlining minimal, weak and strong representationalism, I used the term 'representational' unconjoined to 'content' to elide the difference between the feature of experience view and the representational content view. I will continue to do that in the rest of this essay.

In my opinion, the distinction between the feature of experience view and the representational content view has not been clearly enough made, nor its significance appreciated. For 
example, Chalmers says that the difference between these two views is 'simply a terminological difference' and that 'representationalists' most important claims can be put in the terms used here [the feature of experience way] without loss' (2004: 156). However, this downplays the fundamentally very different accounts of phenomenal character that each of the views puts forward. On both views, phenomenal character characterises what it is it like to have our experiences. It is also said to be that which we are directly aware of in experience. On the feature of experience view we are directly aware of some property of our experience, and thereby - when circumstances are right - indirectly aware of properties in the world. On the representational content view, we are directly aware of the contents of our experience, namely, that which is represented and thereby - in the right circumstances - directly aware of worldly objects and properties. And those, Tye points out, are not properties of experience. Given this, Chalmers is only correct that the feature of experience view and the representational content view are terminological variants of each other if we modified the feature of experience view and held that we are not aware of what that view takes to be the phenomenal character of our experiences - we are not aware of properties of our experience. But it is not obvious that one can do that and still maintain that phenomenal character specifies what it is like to have experience on that view, and it is certainly not the standard way to elucidate the feature of experience view. Thus, while the bumps under the carpet can be flattened at some places for some purposes, they re-emerge in other places.

Moreover, Tye is adamant that it is crucial to understanding the import of his view that we take him to be endorsing the representational content view and not the feature of experience view. In this regard he says:

Arguably, representationalist theories are best understood as rejecting even the basic assumption that the phenomenal character of a state is a property of that state, intrinsic or otherwise . . Buy into the supposition that experiences are inner ideas or pictures viewed by an inner eye and it may be natural to take the 'feel' of an experience to be a property of the idea or picture. But that isn't common sense. It is philosophical dogmaprecisely the dogma which representational theories of phenomenal consciousness oppose. (Tye 2009: 256) 
Here we can also see that Tye wishes to restrict the term 'representationalism' to cover the representational content view, and he doesn't count the feature of experience view as a form of representationalism. This is the first instance of several that we will encounter where people restrict the use of 'representationalism' more tightly than I am in this essay. However, we will see that these people restrict the use in different ways, which lends credence to my to my more liberal characterisation.

To summarise, so far we have seen that there are three forms of representationalism:

(1) Minimal (core claim: some or all phenomenal character is representational; denies (2) and (3))

(2) Weak (core claim: all phenomenal character is representational and the phenomenal supervenes on the representational; denies (3))

(3) Strong (core claim: all phenomenal character is representational and either the phenomenal and representational mutually supervene on each other or the phenomenal and representational are identical).

And we have seen that each of these views can be understood in two different ways. One way interprets the representational as being the property of representing some content. This is the feature of experience way. The other way interprets the representational as being the content of experience itself - that which is represented. See table 1 for a summary.

Some philosophers claim that a view has to endorse (2), weak representationalism, in order to be a form of representationalism. (See, for example, Kind (2003).) Others claim that it has to endorse (3), strong representationalism. (See, for example, Chalmers (2004).) Nonetheless, some people use the term to also cover (1), minimal representationalism.

Table 1 Types of representationalism illustrated showing that minimal, weak and strong representationalist each come in two kinds: the feature of experience view and the representational content view

\begin{tabular}{l|c}
\hline $\begin{array}{l}\text { Feature of } \\
\text { Experience View }\end{array}$ & $\begin{array}{c}\text { Representational } \\
\text { Content View }\end{array}$ \\
\hline Minimal/Weak/Strong & Minimal/Weak/Strong \\
\hline
\end{tabular}


There is one distinction between types of representationalism still to be elucidated: that between reductive and non-reductive representationalism. If one reduces one thing to another then one explains one of the things in terms of the other without remainder. Most reductionist representationalists try to explain phenomenal character in terms of the representational (either in terms of the property of representing certain things or in terms of that which is represented). The aim of reductionists is often to give a naturalistic account of representation, and then to fully explain phenomenal character in terms of it, thereby providing a naturalistic account of phenomenal character. One way to do this is to identify phenomenal character with the representational, yielding reductive strong representationalism. Another way to do this is to claim that that while phenomenal character is not identical to the representational, it supervenes on it and is determined by it in a sense that entails that phenomenal character does not belong to an ontological category distinct from that to which experiential representation belongs. This is reductive weak representationalism.

A naturalist thinks that explanation of phenomena should be continuous with the explanations given in the physical sciences in their present or idealised form. More particularly, they think that objects, properties, and events are spatio-temporal, physical things. To explain things in a naturalistic manner is to explain them solely by reference to spatio-temporal objects and properties and the spatio-temporal relations that such things bear to each other - spatial relations, like being above or being five hundred miles away from, and temporal relations, like being before or being ten years later than - and other relations that science recognises, such as causal relations. ${ }^{8}$

Rather than reduce phenomenal character to the representational, one could try to reduce representation to phenomenal character. However, because of the problems of accounting for consciousness and phenomenal character in a naturalistic manner, this approach has generally been eschewed by naturalists. Nonetheless, a related project has been proposed. On this account, one partially explains the representational in terms of phenomenal character. One does not fully explain it in terms of phenomenal character because no reduction of the nature of

\footnotetext{
A longer and more nuanced discussion of what naturalism is and its metaphysical, epistemological and methodological forms is to be found in Macpherson (2000).
} 
phenomenal character is provided. Nonetheless, phenomenal character is said to 'ground' intentionality, meaning that the former is in some sense explanatorily prior to the latter. One suggestion is that phenomenal character partially constitutes the representational. People who hold such a view include Horgan and Tienson (2002), McGinn (1988), and Siewert (1998).

Non-reductive representationalists attempt no reduction between the phenomenal and the representational or vice versa. It is open to such representationalists to give a naturalist account of phenomenal character, representation, both, or neither.

At this point one might wonder if there could possibly be strong representationalists who identify phenomenal character and the representational, yet who deny reductionism. For one might think that if someone asserts an identity between two things then they are committed to reducing one to another. But this is not the case. Reduction requires more than identity. If one reduces one thing to another, then one explains one of the things in terms of the other, because one thinks that the term used to name that to which one thing is reduced is a term mentioned in a lower-level theory - a more basic or fundamental theory - than the theory which contains the term for that which gets reduced. Consider, for example, asserting an identity between Fiona's favourite colour and Colin's favourite colour. One need not think that one can be explained in terms of the other or think that one is more basic or fundamental. Likewise, when people have asserted an identity between Hesperus and Phosphorous, they have done this without reducing one to the other, for neither of the terms 'Hesperus' or 'Phosphorous' belong to a more fundamental theory than the other. Thus, an identity can be posited without a reduction. Identity is a symmetric relation, whereas the reductive relation is an asymmetric one. Consider that if one identifies water with $\mathrm{H}_{2} \mathrm{O}$, and claims that water can be reduced to $\mathrm{H}_{2} \mathrm{O}$, then one is committed to denying that $\mathrm{H}_{2} \mathrm{O}$ can be reduced to water. Thus, strong representationalists who identify phenomenal character and the representational can either be reductive or non-reductive. The non-reductive representationalists posit an identity but not a reduction. The reductive representationalists will, in addition to identity, posit a reduction. They will hold that the term 'representation' belongs to a lower-level naturalistic theory and the term 'phenomenal character' belongs to a higher-level theory.

Both weak and strong representationalism, and both the feature of experience version and the representational content 
version of each, can come in reductive or non-reductive kinds. Note however, that the minimal view cannot be reductive as its claims about the relationships between phenomenal character and representation are too weak to support a reduction.

Returning to considerations about what views are worthy of the name 'representationalism', some people hold that only reductive forms of representationalism deserve it. One such person is Block (1996: 19), who characterises the distinction between reductive representationalism and all other accounts of the relation between phenomenal character and the representational as '(t) he greatest chasm in the philosophy of mind-maybe even all of philosophy'. However, as we have seen, there are many other views that go under the name 'representationalism'. All these kinds of representationalism are identified in table 2.

I have now laid out the various forms of representationalism. It is not my purpose to weigh up the plausibility of them in this paper. ${ }^{9}$ While many find representationalism plausible, and find the naturalistic picture of the mind that reductive versions of it adhere to attractive, there have been many attempts to undermine representationalism. Some have come from questioning whether some or all experiences represent, others from trying to show that the mutual supervenience of the phenomenal and the representational is false, and others trying to undermine naturalistic accounts of representation, particularly when such accounts have to fully explain phenomenal character as well.

In section three, I outline the sense-data theory and its varieties, before going on, in sections four and five, to ask whether the sense-data view is a form of representationalism.

Table 2 Kinds of Representationalism

\begin{tabular}{l|l|l}
\hline & $\begin{array}{c}\text { Property of } \\
\text { Experience View }\end{array}$ & $\begin{array}{c}\text { Representational } \\
\text { Content View }\end{array}$ \\
\hline Reductionist & Weak/Strong & Weak/Strong \\
\hline Nonreductionist & $\begin{array}{c}\text { Minimal/Weak/ } \\
\text { Strong }\end{array}$ & $\begin{array}{c}\text { Minimal/Weak/ } \\
\text { Strong }\end{array}$ \\
\hline
\end{tabular}

\footnotetext{
9 My own criticisms of representationalism are laid out in Macpherson (2000), (2002), (2003), (2005), and (2006).
} 


\section{The Sense-Data Theory}

The classic sense-data theory of theory of perception goes by many names. It has been called 'indirect realism'. And, confusingly, it has been called 'the representational theory of perception', 'the representative theory of perception', and even simply 'representationalism'. Going by names alone, one might think that the view should have clear affinities with the forms of representationalism that I outlined in section two. While there are some, it is the purpose of this paper to make clear exactly what they are, and what they are not.

I will only use the term 'sense-data theory' to refer to the theory of perception under consideration in this section. This will allow me the terminological ease of being able to inquire as to whether it is a form of representationalism - the view outlined in section two.

According to sense-data theorists, we perceive mindindependent physical objects and properties - such as tables and chairs - indirectly, in virtue of being directly aware of some sensory or mental objects called 'sense-data' ${ }^{10}$ These sense-data represent mind-independent physical objects and their properties. (One can see why the view is also called 'indirect realism' now. According to realism, worldly objects are mind-independent and have at least some of the properties that we take them to have. According to the sense-data theory such mind-independent objects are indirectly perceived..$^{11}$ ) The world we are directly or immediately aware of in perceptual experience is not the external, physical mind-independent world, but merely a mind-dependent internal world, that represents the external world. The representation may be accurate, such as when we perceive the world to be as it is, or inaccurate, such as when we suffer from some illusion or undergo a non-veridical hallucination. (Non-veridical hallucinations are contrasted with veridical hallucinations. Veridical

10 Modern proponents of sense-data theory include Jackson (1977) and Robinson (1994). A famous early version is held by Russell (1912/1998) and (1913). One should note that when Moore $(1953)$ and other theorists in the early $20^{\text {th }}$ century, used the term 'sense-data' they often used it to refer to the direct objects of perception - whatever they turned out to be: mental objects, physical objects, or the surfaces of physical objects. The term 'sense-data' is now, however, used in the way I am using it in this paper: to refer to mental objects that are directly perceived. See Huemer (2011).

11 According to one view that posits sense-data, we do not see, nor are there any mind-independent objects; we are only aware of sense-data. However, I set aside forms of idealism and phenomenalism in this paper. Those views are nicely outlined in Dancy (1985) 
hallucinations are ones that are accurate, perhaps by wild co-incidence, or perhaps because someone has cunningly arranged the world to be as the hallucination represents it to be. ${ }^{12}$ ) It is often thought that the conditions required for indirectly perceiving mind-independent physical objects are that the internal mental objects represent the physical objects accurately, at least to some degree, and that there is an appropriate causal relation between the physical and mental objects. Affirming this is affirming a version of the causal theory of perception.

In the next section, I ask whether the sense-data theory is compatible with minimal representationalist views. In so doing, I begin to tease out different versions of the sense-data view.

\section{Is Sense-Data Theory Compatible with Minimal Representationalism?}

Is the sense-data theory a representationalist theory? In order to address this question, in this section, I consider whether the sensedata theory is compatible with the minimal representationalist claim that at least some phenomenal character is representational. One might have thought that the answer to this question was trivially, yes - for the sense-data view is that sense-data represent mind-independent objects and their properties. However, we have to be careful here. The answer turns out to be far more nuanced.

The answer to the question depends on two things. One is exactly how we unpack the idea that phenomenal character is representational. Recall that there were two ways of doing this: the feature of experience way and the representational content way. This means that there are in fact two distinct questions that the original question masks, either of which one may be interested in asking: (1) is the sense-data theory compatible with the idea that at least sometimes phenomenal character represents something and (2) is the sense-data theory compatible with the idea that at least sometimes phenomenal character is identical to the representational content of experience. The second thing that the answer to the question depends on is what phenomenal character is taken to be on the sense-data view. There are, in fact, two good

12 The nature of hallucination is explored at length in Macpherson (2014). 
candidates. The first is the sense-data themselves and their properties. The second is our awareness of our sense-data and their properties.

These options allow us to set up a two-by-two table, the columns of which represent different forms of representationalism, and the rows of which represent two different forms of sense-data theory each of which corresponds to what one takes phenomenal character to be on the sense-data theory. See table 3 below, which the reader might wish to consult as the various deliberations in this section unfold.

So let us answer each of the two questions in turn. Consider the question: (1) is the sense-data theory compatible with the idea that at least sometimes phenomenal character represents something. Let us suppose first that the phenomenal character of experience is the sense-data themselves and their properties. On this view, clearly the sense-data theory could be a minimal representational view, for sense-data and their properties represent the world (and one need not affirm any stronger relation between phenomenal character and representation). This consideration allows us to fill in the answer in the top left white square of table 3 .

Now let us suppose, secondly, in answering the same question, that the phenomenal character of the experience consists in one's awareness of sense-data and their properties. Thus we are considering how to fill in the answer in the bottom left white square in table 3. Does this awareness represent anything? Is the relation of awareness that one bears to one's sense-data a representational relation? If so, then, this would be another sense in which the sense-data view would be a minimal representational view.

Byrne (2001) has claimed that the sense-data view is a representational view on the grounds that I have just been considering. ${ }^{13}$ He claims that the phenomenal character of experience on the sense-data view consists of awareness of sense-data. And he argues that this awareness relation is a representational relation. But is Byrne right to think that the relation between oneself and one's sense-data is a representational relation? I will answer this

13 Byrne (2001) does not distinguish between minimal, weak and strong forms of representationalism, but presumably if he says that the sense-data theory is compatible with representationalism tout court then he would at least think it compatible with minimal representationalism. 
Table 3 Whether the Sense-Data View is compatible with a Minimal Representationalist View

\begin{tabular}{|c|c|c|}
\hline & $\begin{array}{c}\text { Feature of } \\
\text { Experience View }\end{array}$ & $\begin{array}{c}\text { Representational } \\
\text { Content View }\end{array}$ \\
\hline \multirow[t]{2}{*}{$\begin{array}{l}\text { Phenomenal } \\
\text { character is the } \\
\text { sense-data and } \\
\text { their properties }\end{array}$} & \multirow[t]{2}{*}{$\begin{array}{l}\text { Compatible with } \\
\text { minimal } \\
\text { representationalist } \\
\text { view }\end{array}$} & $\begin{array}{l}\text { The content of } \\
\text { experience is the } \\
\text { sense data } \\
\qquad= \\
\text { Compatible with } \\
\text { minimal } \\
\text { representationalist } \\
\text { view }\end{array}$ \\
\hline & & $\begin{array}{l}\text { The content of } \\
\text { experience is } \\
\text { mind-independent } \\
\text { objects } \\
\text { Not compatible } \\
\text { with a minimal } \\
\text { representationalist } \\
\text { view }\end{array}$ \\
\hline \multirow[t]{2}{*}{$\begin{array}{l}\text { Phenomenal } \\
\text { character is } \\
\text { awareness of the } \\
\text { sense-data and } \\
\text { their properties }\end{array}$} & $\begin{array}{l}\text { Acquaintance is } \\
\text { not a form of } \\
\text { representation } \\
= \\
\text { Not compatible } \\
\text { with a minimal } \\
\text { representationalist } \\
\text { view } \\
\end{array}$ & \multirow[t]{2}{*}{$\begin{array}{l}\text { Not compatible } \\
\text { with a minimal } \\
\text { representationalist } \\
\text { view }\end{array}$} \\
\hline & $\begin{array}{l}\text { Acquaintance is } \\
\text { a form of } \\
\text { representation } \\
\quad= \\
\text { Compatible with } \\
\text { a minimal } \\
\text { representationalist } \\
\text { view }\end{array}$ & \\
\hline
\end{tabular}


by considering how one might understand 'acquaintance', the relation between oneself and one's sense-data that Russell, one of the main expositors of the sense-data view, proposed.

As conceived of by Russell (1912/1998), the relationship that one bears to one's sense-data in being aware of them is acquaintance. A test for whether one is acquainted with something is whether one can sensibly doubt that the candidate object of acquaintance does not exist, given one's evidence. ${ }^{14}$ Only if one cannot so doubt, can one be acquainted with the thing. Therefore, the test provides only a necessary condition for the presence of acquaintance. It does not provide a sufficient condition. What else does Russell say about acquaintance? He claims that it is a primitive relation - a simple fundamental relation not explicable by others. Does saying this much about acquaintance allow us to determine whether it should be contrasted with representation or whether it should be seen as a particular form of representation a form of representation of mental objects? That is a difficult question to settle.

On one reading of Russell's view, it would be tempting to think that acquaintance and representation should be contrasted. Russell is keen to distinguish acquaintance from judgement, which clearly involves representation, and is the paradigm of the representational state. Acquaintance is a relation that a subject bears to a single object - a sense-datum - claims Russell. Because it is a two-term relation, he claims there is not a question of whether the sense-datum exists, nor a question of whether the relation can be true or false or accurate or inaccurate.$^{15}$ When you, for example, experience 'the redness of this', and hence are acquainted with your sense-datum, according to Russell, there is a relation between you and one single, although complex, object, 'the redness of this'. ${ }^{16}$ In contrast, Russell thinks that judgement is a relation to a proposition, which is composed of more than one object. When you judge 'this is red' there is a relation between you and red and this (between you and two objects). And Russell says that such a relation can be true or false: 'In the case of judgment, error can arise; for although the several objects of the judgment

14 This is the orthodox test. See, for example, Fumerton (2009). An interesting question, and a place at which disagreement may arise, is what one should take one's evidence to be when applying the test.

15 See Russell (1913: 76), quoted in Savage (1989: 140).

16 See Whitehead and Russell (1910) cited in Savage (1989: 141). 
cannot be illusory, they may not be related as the judgment believes that they are. ${ }^{17}$

Given this, one might think that on Russell's view, acquaintance is not representation because (i) acquaintance guarantees that one cannot doubt the existence of what one is acquainted with, but representation does not guarantee that one cannot doubt the existence of what one represents and, (ii) acquaintance is a relation to an object, which is not something that can be true or false, while representation is a relation that one bears to something that can be true or false - a proposition. If that is correct, then on Russell's view, acquaintance is not representation.

However, Byrne (2001) claims that there is no good reason to accept the claim that representation requires the possibility of misrepresentation. Beliefs in necessary truths (such as two plus two equals four) and the Cogito (I think therefore I am) provide counterexamples. When one believes these things there is no possibility that they could be false, and, in the case of the Cogito, one can plausibly argue, as Descartes did, that one cannot doubt it to be true. Thus, Byrne is arguing that representation need not be the way that it is characterised in (i) and (ii) above. If Byrne is right, then it has not been shown that acquaintance should not be thought of as a form of representation.

However, even if Byrne is right that that representation does not require the possibility of misrepresentation, nonetheless, a difference that Russell highlights between acquaintance and representation remains. For Russell, acquaintance is a relation between a person and an object. Representation is a relation between a person and a proposition that is composed of more than one object. Someone wishing to defend Byrne's position could argue that Russell is misguided in what either the objects of acquaintance or the objects of representation are.

One could try to do this by claiming that acquaintance is representation in perceptual form. For example, Byrne (2001) claims that we should understand perceptual representation as occurring whenever things seem a certain way to a subject. According to this understanding, Byrne claims, because sense-data will always seem a certain way to a subject they will be represented to the subject. If one accepts this then one could hold that acquaintance is a relation between a person and one object but hold that representation can also be a relation between a person and one

17 Russell (1913: 76) quoted in Savage (1989: 140). 
object, say the complex object "the redness of this". Alternatively, one could hold that both representation and acquaintance involve relations between a person and a proposition, rather than an object. In the case of acquaintance, one could hold that a subject's experience will represent, say, that there is a red sensedatum, and in so doing relate the subject to the proposition that there is a red sense-datum.

However, Byrne's notion of representation, as occurring whenever things seem a certain way to a subject, is not uncontroversial. For example, his notion of representation has been challenged by Pautz (2009) on the grounds that it trivialises the debate concerning whether experiences represent and have contents. On Byrne's notion of representation, perceptual experiences could not fail to have contents, says Pautz, and so the question of whether (even minimal) representationalism is true or not becomes entirely trivial and not one that is open to debate. Pautz goes on to develop his own conception of representation - the identity conception, the complex details of which need not be explored here - according to which sense-data are not represented in experience (2009: 493).

What we can see from this discussion is that the question of whether we each bear a representational relation to our own sense-data is a question that is highly sensitive to the exact way that one spells out the nature of representation. Those in favour of the view that we do will hold a very weak notion of representation that allows such cases to count. Those that do not will complain that such a view cannot be what is at issue in determining whether we represent our own sense-data precisely because the view trivially entails that we represent our own sense-data. Those people will insist on a more demanding notion of representation.

To summarise where we are, recall that we were considering the first of two questions: (1) is the sense-data theory compatible with the idea that at least sometimes phenomenal character represents something. What we have seen is that if we take phenomenal character to be the sense-data and their properties the answer is yes. If we take the phenomenal character to be the relation of awareness that we bear to our sense-data then the answer is unclear. Some people, like Byrne, will answer yes as they think that this relation is a representational relation. Others will resist this, arguing that this relation is a special relation of acquaintance that should be distinguished from representation. The left-hand white column of table 3 summarises these results. 
Let us now consider our second question: (2) is the sense-data theory compatible with the idea that at least sometimes phenomenal character is identical with the representational content of experience. Again the answer will vary depending on whether one takes the phenomenal character of experience to be the sensedata and their properties or the relation of awareness that we bear to our sense-data.

If one takes the former view of phenomenal character then there are two distinct answers that one could give, depending on what one takes the content of the experience to be. If one takes the content of one's experience to be the sense-data and their properties because one thinks of one's awareness of sense-data as a representational relation then the sense-data and their properties would be representational contents - so the answer to the question would be yes.

If one takes the content of one's experience to be mindindependent objects in the world - and one is asking whether sense-data are to be identified with that (either because one doesn't think that one's sense data are contents or because one takes one's experience to have two levels of content: both sense-data and mind-independent objects) then phenomenal character will not be the representational content of one's experience.

The way to see this last point clearly is to distinguish between vehicles and content. When used appropriately, the word 'hamster' represents the kind hamster. The vehicle is the printed word on the page or the sound of the spoken word (the thing that does the representing) and that which is represented is a kind of small loveable furry animal. According to the version of the sensedata theory under consideration, sense-data and their properties are vehicles of representation for contents that are mindindependent objects. Were I to see a hamster, according to this theory, I would have a certain sense-datum that I am aware of that is a vehicle that represents a hamster - a hamster that is a content of the experience. And, recall, that on the view under consideration, phenomenal character consists in the sense-datum and its properties (the vehicle) not what is represented (a hamster). Thus the answer to the question of whether this version of the sense-data theory is compatible with minimal representationalism is no.

The results of our considerations so far about the second question are summarised in the top right white box of table 3 . 
Finally, if one takes the view that the phenomenal character of experience is the relation of awareness that we bear to our sensedata, then the answer will be that the sense-data view is not a minimal representational view, for whether or not this relation is one of representation or a distinctive one of acquaintance, in no way is the awareness itself the representational content of experience. This result is recorded in table 3 in the bottom right white box.

To summarise the response to question (2), is the sense-data theory compatible with the idea that at least sometimes phenomenal character is identical with the representational content of experience, the answer in all but one case is no. If one takes the content of one's experience to be the sense-data because one thinks of one's awareness of sense-data as a representational relation then the sense-data and their properties would be representational contents, so the answer to the question would be yes. But on all other views of what the content of experience is, the answer is no.

Overall, therefore, there are some senses in which the sensedata view is compatible with a minimal representationalist view and some senses in which it is not a representationalist view at all. This is because of the different interpretations of what being a minimal representationalist view is, the different accounts of the nature of phenomenal character on the sense-data view, and the different accounts of representation itself.

In this section the discussion has been about the relationship between sense-data theory and minimal representationalism. In the next section, I turn to consider what the relationship is between sense-data theory and weak, strong, and reductive representationalism.

\section{Is Sense-Data Theory Compatible with Weak, Strong, and Reductive Representationalism?}

Now that we have a grip on the relationship between sense-data theory and minimal representationalism, we can see that forms of sense-data theory could be developed that were forms of weak and forms of strong representationalism. In every instance in which the sense-data view is compatible with minimal representationalism, one could simply add specifications to one's sense-data theory of the relations between the phenomenal character of the 
experience and what one's sense-data represent required for either weak or strong representationalism. For example, suppose that one held that phenomenal character is identical to sense-data and their properties. One could hold that all perceptual experience involves sense-data that represent the mind-independent world and that the phenomenal character of one's experience supervenes on what one's sense-data represent. However, note that such a view is not mandatory; one could equally develop a sense-data theory incompatible with a weak feature of experience version of representationalism. One might do so because one wishes to hold that the same sense-data, or the same types of sense-data, can represent different things on different occasions.

Likewise, one could develop versions of sense-data theory that were forms of strong representationalism. For example, one could hold that one's sense-data and their properties always represent, and that the phenomenal character of one's experience and what one's sense-data represent mutually supervene. Here is another example: one could hold that all phenomenal character involves representing one's sense-data, and that the phenomenal character of one's experience, and how one's sense-data are represented to be, mutually supervene on each other, and are in fact identical to one another. These would be strong feature of experience forms of representationalism. Again, however, clearly such a view is not mandatory and many versions of sense-data theory will not be strong representationalist views.

Finally, the sense-data view is clearly not a naturalist reductive representationalist view. Recall that the aim of naturalist reductionist representationalist theories is to give a naturalistic account of representation and then to fully explain consciousness and phenomenal character in terms of representation, thus providing a naturalistic account of phenomenal character. The sensedata theory takes sense-data to be non-physical mental objects that have properties, and that do not exist in physical space. Hence a naturalistic characterisation of them cannot be given. The phenomenal character of an experience consists in either the sensedata and their properties, or in being aware of sense data and their properties. Phenomenal character is not, therefore, on the sense-data view, something that could receive a naturalistic explanation, nor is an explanation of it given solely in terms of representation.

Could one hold a non-naturalist reductive representationalist sense-data view? Recall that there are two forms of non-naturalist 
reductive representationalist views. According to one view, phenomenal character can be reduced to representation. According to another view, representation can be reduced to phenomenal character.

If one held a version of weak or strong representationalism then either of these positions would be open to one to hold if one were a sense-data theorist, if one could find reasons to think that one or other notion was explanatorily more basic.

\section{Conclusion}

In section two, we saw that people applied the term 'representationalism' to different theories. We saw that some people withheld the name 'representationalism' from the view I have called 'minimal representationalism', others withheld the name from feature of experience forms of representationalism, and others still withheld the name from non-reductive representationalism. Moreover, we have seen, in section three, that there are various views of what phenomenal character is on the sense-data theory, and various views about what acquaintance and representation are. Given this, it is no surprise that the question of whether sense-data is a form of representationalism has been given very different answers in the literature. This paper has explained these differences in detail and, I believe fully addressed the question of whether the sense-data theory is a form of representationalism.

\section{Philosophy \\ University of Glasgow \\ Glasgow \\ G12 8QQ \\ United Kingdom}

\section{References}

Bayne, T. and Montague, M. (2011). Cognitive Phenomenology, Oxford: Oxford University Press.

Block, N. (1996). 'Mental Paint and Mental Latex', in E. Villaneuva (ed.) Philosophical Issues

7, Perception. Atascadero, Calif.: Ridgeview, 19-49.

Byrne, A. (2001). "Intentionalism Defended" The Philosophical Review, 110(2): 199-240.

Chalmers, D. (2004). 'The Representational Character of Experience', in B. Leiter (ed.) The Future for Philosophy, Oxford: Oxford University Press.

Dancy, J. (1985). An Introduction to Contemporary Epistemology, Oxford: Blackwell. 
Dretske, F. (1995). Naturalising the Mind. Cambridge, MA: MIT Press.

Fumerton, R. (2009). 'Knowledge by Acquaintance Vs. Description', in E. N. Zalta (ed.) The Stanford Encyclopedia of Philosophy (Summer 2009 Edition), http://plato.stanford.edu/ archives/sum2009/entries/knowledge-acquaindescrip.

Horgan, T. and Tienson, J. (2002). 'The Intentionality of Phenomenology and the Phenomenology of Intentionality', in D. Chalmers (ed.) Philosophy of Mind: Classical and Contemporary Readings. Oxford: Oxford University Press.

Huemer, M. (2011). 'Sense-Data', The Stanford Encyclopedia of Philosophy (Spring 2011 Edition), in E. N. Zalta (ed.), URL $=<$ http://plato.stanford.edu/archives/spr2011/ entries/sense-data/>.

Jackson, F. (1977). Perception: A Representative Theory. Cambridge: Cambridge University Press.

Kind, A. (2003). 'What's So Transparent About Transparency?' Philosophical Studies 115: 225-244.

Lycan, W. G. (2006). 'Representational Theories of Consciousness', Stanford Encyclopedia of Philosophy. http://plato.stanford.edu/entries/consciousness-representational/ (accessed July 2012).

Macpherson, F. (2000). Representational Theories of Phenomenal Character, University of Stirling PhD Thesis, available on the Stirling Online Research Repository at http:// hdl.handle.net/1893/25.

Macpherson, F. (2002). 'The Power of Natural Selection', Journal of Consciousness Studies, Vol. 9, No. 8, pp. 30-35.

Macpherson, F. (2003). 'Novel Colours and the Content of Experience', Pacific Philosophical Quarterly, Vol. 84, No. 1, pp. 43-66.

Macpherson, F. (2005). 'Colour Inversion Problems for Representationalism', Philosophy and Phenomenological Research, Vol. 70, No. 1, pp. 127-152.

Macpherson, F. (2006). 'Ambiguous Figures and the Content of Experience', Noûs, Vol. 40, No. 1, pp. 82-117.

Macpherson, F. (2011). 'Cross-Modal Experiences', Proceedings of the Aristotelian Society, Volume 111 (3): 429-468.

Macpherson, F. (2014). 'Hallucination: An Introduction', in F. Macpherson and D. Platchias (eds.) Hallucination: Philosophy and Psychology, MIT Press.

McGinn, C. (1988). 'Consciousness and Content', Proceedings of the British Academy, 74: 219-239.

Moore, G. E. (1953). Some Main Problems of Philosophy, London: George, Allen and Unwin.

Nagel, T. (1974). 'What is it Like to be a Bat?' Philosophical Review 83(4): 435-50.

Pautz, A. (2009). 'What Are the Contents of Experiences?', The Philosophical Quarterly, 59(236): 483-507.

Robinson, H. (1994). Perception. London: Routledge.

Russell, B. (1912/1998). The Problems of Philosophy. Oxford: Oxford University Press.

Russell, B. (1913). 'The Nature of Sense-Data - A Reply to Dr Dawes Hicks', Mind, 22(85): $76-81$.

Savage, C. W. (1989). 'Sense-Data in Russell's Theory of Knowledge', Minnesota Studies in Philosophy of Science, 12: 138-168.

Siewert, C. (1998). The Significance of Consciousness, Princeton: Princeton University Press.

Tye, M. (1995). Ten Problems of Consciousness. Cambridge, MA: MIT Press.

Tye, M. (2000). Consciousness, Color, and Content. Cambridge, MA: MIT Press.

Tye, M. (2009). 'Representationalist Theories of Consciousness', in B. McLaughlin, A. Beckermann, and S. Walter (eds.) The Oxford Handbook of Philosophy of Mind, Oxford: Oxford University Press.

Whitehead, A. N. and Russell, B. (1910). Principia Mathematica: Volume 1, Cambridge University Press. 